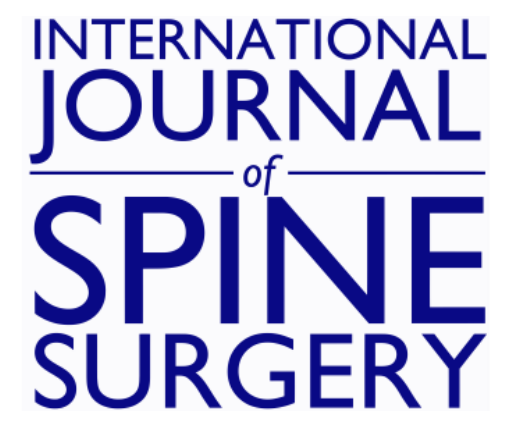

\title{
Prospective, Randomized Comparison of One-level Mobi-C Cervical Total Disc Replacement vs. Anterior Cervical Discectomy and Fusion: Results at 5-year Follow-up
}

Michael S. Hisey, Jack E. Zigler, Robert Jackson, Pierce D. Nunley, Hyun W. Bae, Kee D. Kim and Donna D. Ohnmeiss

Int J Spine Surg 2016, 10 ()

doi: https://doi.org/10.14444/3010

http://ijssurgery.com/content/10/10

This information is current as of April 26, 2023.

Email Alerts Receive free email-alerts when new articles cite this article. Sign up at:

http://ijssurgery.com/alerts

The International Journal of Sping Surgerbhttp://ijssurgery.com/ by guest on April 26, 2 2397 Waterbury Circle, Suite 1, 


\section{Prospective, Randomized Comparison of One-level Mobi-C Cervical Total Disc Replacement vs. Anterior Cervical Discectomy and Fusion: Results at 5-year Follow-up}

Michael S. Hisey, MD, ${ }^{1}$ Jack E. Zigler, MD, ${ }^{2}$ Robert Jackson, MD, ${ }^{3}$ Pierce D. Nunley, MD, ${ }^{4}$ Hyun W. Bae, MD, ${ }^{5}$ Kee D. Kim, MD, ${ }^{6}$ Donna D. Ohnmeiss, Dr.Med. ${ }^{7}$

${ }_{1}^{1}$ Texas Back Institute, Denton, Texas, ${ }^{2}$ Texas Back Institute, Plano, Texas, ${ }^{3}$ Saddleback Memorial Medical Center, Laguna Hills, California, ${ }^{4}$ Spine Institute of Louisiana, Shreveport, Louisiana, ${ }^{5}$ Cedars Sinai Spine Center, Los Angeles, California, ${ }^{6}$ Department of Neurological Surgery, University of California, Davis, Sacramento, California, ${ }^{7}$ Texas Back Institute Research Foundation, Plano, Texas

\section{Abstract}

\section{Introduction}

There is increasing interest in the role of cervical total disc replacement (TDR) as an alternative to anterior cervical discectomy and fusion (ACDF). Multiple prospective randomized studies with minimum 2 year follow-up have shown TDR to be at least as safe and effective as ACDF in treating symptomatic degenerative disc disease at a single level. The purpose of this study was to compare outcomes of cervical TDR using the Mobi-C ${ }^{\circledR}$ with ACDF at 5-year follow-up.

\section{Methods}

This prospective, randomized, controlled trial was conducted as a Food and Drug Administration regulated Investigational Device Exemption trial across 23 centers with 245 patients randomized (2:1) to receive TDR with Mobi$\mathrm{C}^{\circledR}$ Cervical Disc Prosthesis or ACDF with anterior plate and allograft. Outcome assessments included a composite overall success score, Neck Disability Index (NDI), visual analog scales (VAS) assessing neck and arm pain, Short Form-12 (SF-12) health survey, patient satisfaction, major complications, subsequent surgery, segmental range of motion, and adjacent segment degeneration.

Results

The 60-month follow-up rate was $85.5 \%$ for the TDR group and $78.9 \%$ for the ACDF group. The composite overall success was $61.9 \%$ with TDR vs. $52.2 \%$ with ACDF, demonstrating statistical non-inferiority. Improvements in NDI, VAS neck and arm pain, and SF-12 scores were similar between groups and were maintained from earlier follow-up through 60 months. There was no significant difference between TDR and ACDF in adverse events or major complications. Range of motion was maintained with TDR through 60 months. Device-related subsequent surgeries (TDR: $3.0 \%$, ACDF: $11.1 \%, \mathrm{p}<0.02$ ) and adjacent segment degeneration at the superior level (TDR: $37.1 \%$, ACDF: $54.7 \%, \mathrm{p}<0.03)$ were significantly lower for TDR patients.

\section{Conclusions}

Five-year results demonstrate the safety and efficacy of TDR with the Mobi-C as a viable alternative to ACDF with the potential advantage of lower rates of reoperation and adjacent segment degeneration, in the treatment of onelevel symptomatic cervical degenerative disc disease.

\section{Clinical Relevance}

This prospective, randomized study with 5-year follow-up adds to the existing literature indicating that cervical TDR is a viable alternative to ACDF in appropriately selected patients.

Level of Evidence

This is a Level I study.

KEYWORDS: TOTAL DISC REPLACEMENT, CERVICAL SPINE, ANTERIOR CERVICAL FUSION, DEGENERATIVE DISC DISEASE, MOBI-C ${ }^{\circledR}$ CERVICAL DISC PROSTHESIS, CERVICAL ARTHROPLASTY, ARTIFICIAL DISC, RANDOMIZED TRIAL, CLINICAL OUTCOME 


\section{Introduction}

Pain arising from degenerative changes in the cervical spine can be very debilitating. If nonoperative treatment fails to yield adequate relief, anterior cervical discectomy and fusion (ACDF) is generally the surgical option undertaken. Due to the potential for post-fusion problems such as pseudoarthrosis and adjacent segment degeneration (ASD), an alternative treatment was sought, leading to the development of cervical total disc replacement (TDR). The goal of TDR as a surgical intervention was to reduce pain and restore function, allow motion of the operated segment, avoid the potential problem of pseudoarthrosis, and eliminate or reduce the incidence of adjacent segment degeneration (ASD).

There have been multiple publications reporting the clinical outcome of cervical TDR, including reporting results of prospective, randomized, multicenter trials with 24-month follow-up. ${ }^{1-8}$ These studies have consistently found TDR to produce outcomes similar or superior to ACDF. There are a few studies with extended follow-up to five or more years. ${ }^{9-12}$ Results of these long-term studies have been consistent in that the favorable outcomes seen at 2 years after surgery were maintained throughout the longer follow-up.

Cervical TDR has been found to be associated with a significantly lower reoperation rate ${ }^{13-15}$ as well as reduced occurrence of ASD compared with ACDF. ${ }^{1,5}$ However, some authors have reported no significant difference in ASD. ${ }^{16}$ More randomized studies with long-term follow-up should be helpful in further evaluating cervical TDR. The purpose of this study was to compare clinical outcomes at 5 years after surgery using TDR with the Mobi-C or ACDF in the treatment of single-level symptomatic disc degeneration based on a prospective, randomized Food and Drug Administration regulated Investigational Device Exemption trial.

\section{Methods}

This study was a prospective, randomized, controlled, multicenter clinical trial comparing the safety and efficacy of TDR with the Mobi-C ${ }^{\otimes}$ Cervical Disc Prosthesis (LDR Medical; Troyes, France) to ACDF for the treatment of single-level symptomatic degenerative disc disease (DDD). Patients were randomized in a 2:1 ratio to receive TDR $(n=164)$ or ACDF $(\mathrm{n}=81$, the control treatment). The study was conducted at 23 sites across the United States. The study design, including patient selection criteria, randomization and surgical procedures, has previously been published in detail. ${ }^{5}$

\section{Patient Population}

Eligible patients met the primary inclusion criteria of symptomatic DDD with radiculopathy or myeloradiculopathy at one level from $\mathrm{C} 3$ to $\mathrm{C} 7$, disc height of at least $3 \mathrm{~mm}$, not osteoporotic, no previous cervical fusion, and failure of at least 6 weeks of nonoperative care.

\section{Study Interventions}

The TDR investigational device was the Mobi-C ${ }^{\circledast}$ Cervical Artificial Disc. The control treatment was ACDF performed with either the Slim-Loc Anterior Cervical Plate System (Depuy Spine) or the Sofamor Danek Atlantis or Atlantis Vision Anterior Cervical Plate Systems (Medtronic) with corticocancellous allograft in the interbody space.

\section{Study Outcomes}

Outcomes were evaluated preoperatively and at 6 weeks, 3, 6, 12, 18, 24, 36, 48 and 60 months postoperatively. The success endpoint used in this analysis was defined with the approval of the FDA within the Post Approval Study (PAS) protocol. This endpoint differs from our previously published definition at earlier follow-up points. ${ }^{5,17}$ The primary outcome measure was a composite success criterion requiring patients to meet all of the following to be classified as having a successful outcome: 1) minimum 30/100 point improvement in NDI scores compared to baseline; 2) No device-related subsequent surgery; 3) No adverse events (AEs) classified as possibly or probably device-related by an independent Clinical Events Committee (CEC); 4) No neurologic deterioration; and 5) No intraoperative changes in treatment if randomized to Mobi-C. A device-related subsequent surgery was defined as any device removal, revision, 
supplemental fixation, or reoperation at the index level. Adverse events were classified by the CEC composed of 3 independent spine surgeons (two orthopedic surgeons and one neurosurgeon).

Secondary outcome evaluations included visual analog scale (VAS) separately assessing neck and arm pain, quality of life assessed by the Short Form Health Survey (SF-12), and patient satisfaction and recommendation assessed through a patient questionnaire. Neurologic deterioration, adverse events, radiographic failure, subsequent surgery (including those that were not device-related), segmental range of motion (ROM), adjacent segment degeneration, and heterotopic ossification (HO) were evaluated postoperatively through 60 months. For TDR treatment, radiographic failure was defined as spontaneous fusion with radiographic evidence of bridging bone across the disc space and less than $2^{\circ}$ of angular motion on flexion/extension. For ACDF treatment, radiographic failure was defined as at least $2^{\circ}$ of angular motion on flexion/extension, or radiolucencies at more than $50 \%$ of the graft vertebral body interface, or absence of bridging bone across the graft vertebral body interfaces. ASD was assessed using the Kellgren-Lawrence scale of disc degeneration. ${ }^{18} \mathrm{~A}$ patient was classified as having adjacent segment degeneration if there was a deterioration of at least one point on the Kellgren-Lawrence scale compared with the score for the preoperative radiograph. HO was graded using a 0 to 4 scale adapted from the methods described by McAfee et al. ${ }^{19}$ and Mehren et al. ${ }^{20}$ Since the primary concern with $\mathrm{HO}$ is the potential for fusion and restricted motion, the percentage of patients in the TDR group with Grade $4 \mathrm{HO}$ (continuous bridging bone between vertebral bodies resulting in bony ankylosis and resulting in little or no motion at the index level) was calculated. All radiographic assessments were made by an independent evaluator (Medical Metrics, Houston, TX).

\section{Statistical Analysis}

This study was designed as a non-inferiority trial with the primary study hypothesis testing the noninferiority of TDR with Mobi-C against ACDF using a $10 \%$ margin with respect to patient success at 60 months. Non-inferiority in the overall success rate was assessed using an exact 95\% one-sided confi- dence bound. Statistical significance in success criteria and incidence rates was determined using Fisher's exact test. Statistical significance of continuous outcome measures was assessed by two-sided t-tests at each time point. Changes from baseline within treatment groups were evaluated by Wilcoxon signed-rank test to determine significance. Statistical significance was indicated by a p-value less than 0.05 .

\section{Results}

No significant differences were found between the baseline demographics of patients in the two treatment groups. ${ }^{5}$ The 60-month follow-up rate was $85.5 \%$ for the TDR group and $78.9 \%$ for the ACDF group.

\section{Primary Endpoint: Composite Success Criteria} At 60 months, $61.9 \%$ of TDR patients and $52.2 \%$ of ACDF patients were classified as having achieved overall success. Based on the composite success criteria, TDR was non-inferior to ACDF at all postoperative evaluation points through 60 -month followup. A higher percentage of TDR patients met the overall success criteria at each time point, although the differences were not statistically significant.

\section{Components of Composite Success}

When considering the percentage of patients who met the NDI criterion used to determine composite success, the values were $68.1 \%$ in the TDR group and $62.1 \%$ for ACDF at the 60 month follow-up. At 60 months, the rate of device-related subsequent surgery was significantly less for the TDR group compared with ACDF (3.0\% vs. 11.1\%; p <0.05; Fisher's exact test). The rate of device-related adverse events as classified by the CEC were statistically similar between treatment groups at 60 months (TDR: 5.5\%, ACDF: $3.7 \%$ ), as was the rate of neurological deterioration (TDR: $4.3 \%$, ACDF: 6.2\%). There were no changes in planned surgery in the Mobi-C group.

\section{Secondary Endpoints \\ NDI Scores}

The mean NDI scores improved significantly by 6 weeks after surgery and remained significantly improved throughout 60 month follow-up in both groups (Figure 1). Of note, scores remained very sta-

Downloaded from http://ijssurgery.com/ by guest on April 26, 2023 
ble throughout the multi-year study. While the only significant differences between the two groups occurred at early follow-up points, at no time point were the mean scores in the TDR group worse than in the ACDF group.

\section{VAS Pain Scales}

VAS neck pain scores improved significantly from baseline at all follow-up points in both treatment groups. Preoperatively, in both groups the mean values were approximately 70, and were less than 20 at 60-month follow-up (Figure 2A). The mean values remained very stable throughout follow-up with no indication of worsening at later follow-up visits.

VAS arm pain scores for the more symptomatic arm followed a pattern very similar to neck pain values. In both treatment groups, the mean arm pain scores improved significantly at all follow-up visits compared with the preoperative values and were stable over 5 years (Figure 2B).

\section{SF-12 Scores}

The preoperative SF-12 PCS values were 32.5 and 33.8 in the TDR and ACDF groups, respectively. These scores improved significantly by 6 months after surgery and remained improved throughout 60-month follow-up to values of 47.6 and 48.3 in the two groups. The values were stable throughout annual follow-up with changes of less than 2 points in the TDR scores throughout the long-term follow-up and less than a 3-point change in ACDF scores across all annual visits. The SF-12 MCS followed a similar pattern with significant and sustained improvement in both groups throughout 60-month follow-up.

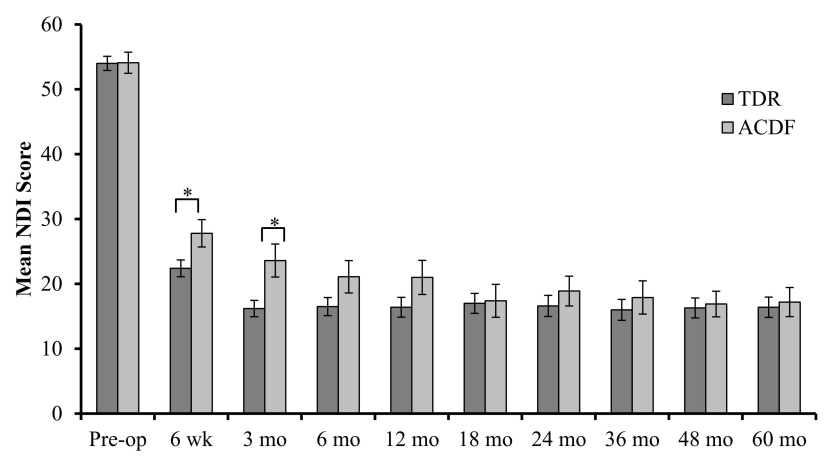

Fig. 1. Mean NDI scores of TDR and ACDF at each follow-up. * Statistical significance determined by Student's t-test, $\mathrm{p}<0.05$.

\section{Subsequent Surgery}

In addition to the device-related subsequent surgery criteria used to determine the composite success rate, other surgeries at the index and adjacent levels were also recorded. By 60 month follow-up, 8 patients (4.9\%) in the TDR group and 14 patients (17.3\%) in the ACDF group underwent subsequent surgery ( $\mathrm{p}<0.01$; Fisher's exact test). Of the 8 reoperations in the TDR group, one patient underwent laminectomy at the TDR level due to nerve impingement. In 4 cases the TDR was removed and fusion performed. Reasons for disc removal and fusion included oversized implant, development of heterotopic ossification causing pain during flexion/extension movements, and the development of kyphosis due to a malpositioned device. Two of these patients with secondary fusion later required a tertiary surgery to revise the ACDF. The remaining 3 subsequent surgeries in the TDR group were performed to treat symptoms arising from the level adjacent to the TDR level.

Of the 14 ACDF secondary surgeries, 5 were to treat symptomatic pseudoarthrosis, 6 patients had surgery to treat symptoms arising from an adjacent segment,
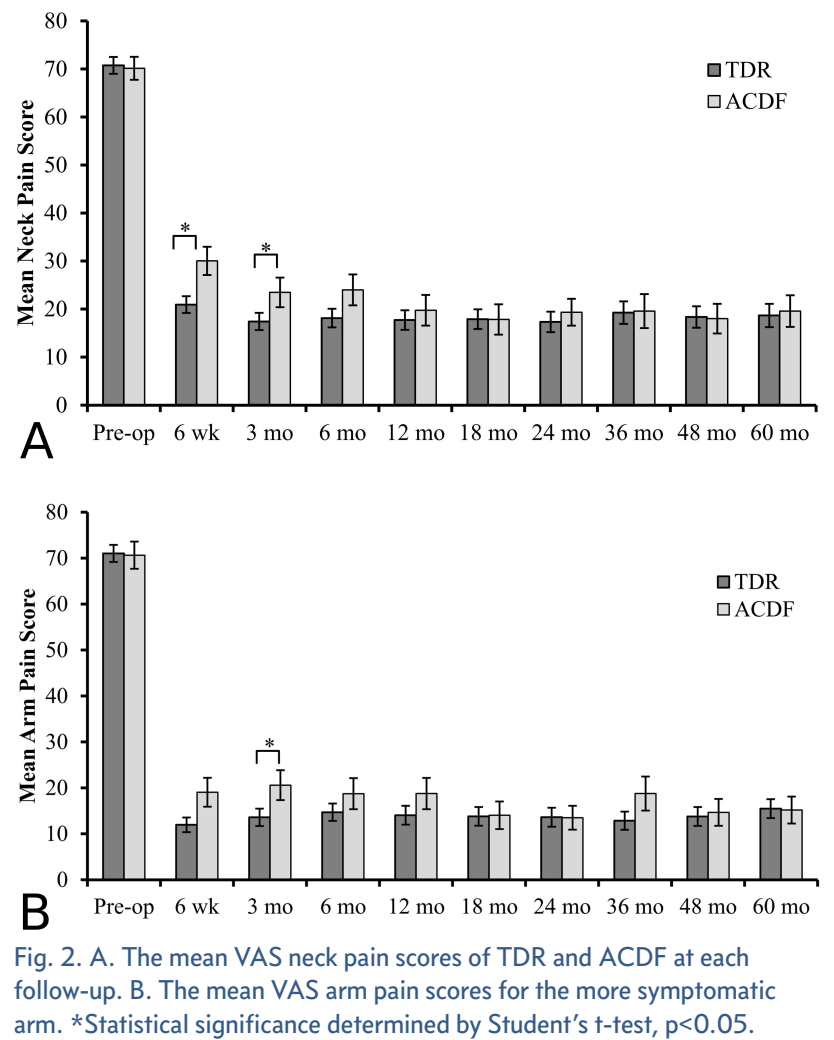
one patient underwent surgery to treat stenotic symptoms, one patient required surgery to address a malpositioned screw, and one patient had surgery 5 days after the index procedure to evacuate a hematoma. One tertiary surgery was performed to expand the fusion to adjacent levels. A detailed description of subsequent surgeries in the total safety population (randomized cases and training cases) has been published by Jackson et al. ${ }^{21}$

\section{Patient Satisfaction}

Overall, patient satisfaction and recommendation rates were high for both groups at every time point. At 60 months, $92.0 \%$ of TDR patients and $83.9 \%$ of ACDF patients were very satisfied with their treatment (Figure 3). There was very little change in the distribution in scores across the 4 response categories for satisfaction across multiple follow-up time points. The rate of patients recommending their treatment to a friend was also high in both treatment groups with $97.1 \%$ of TDR patients and $91.1 \%$ of ACDF patients indicating they would definitely or probably recommend the treatment they received.

\section{Radiographic Assessment}

There were no cases of device migration in either treatment group. The occurrence of radiographic failure was similar between TDR (5.5\%) and ACDF (3.7\%). At 60-month follow-up, 95.2\% of TDR subjects and $98.1 \%$ of ACDF subjects were classified as having no radiolucency around the implants. In the TDR group, the radiolucencies noted were mild in all cases and in the ACDF group, the one radiolucency noted was severe.

Segmental ROM at the treated level was maintained

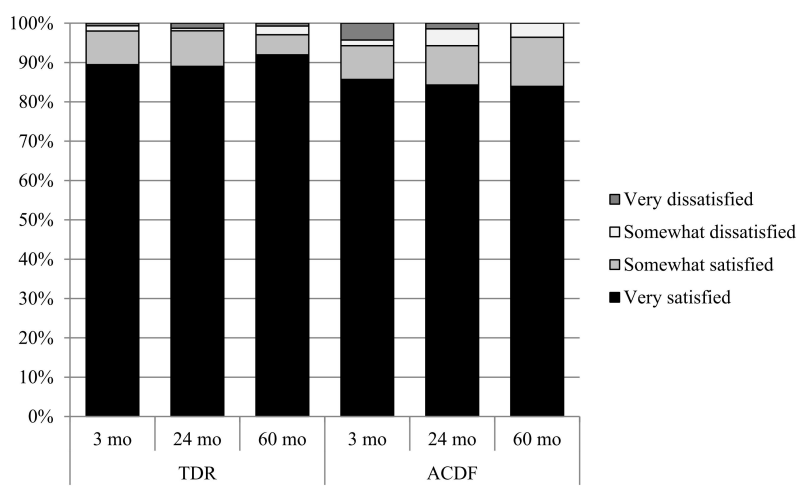

Fig. 3. Distribution of responses to the satisfaction question. in the TDR group throughout 60-month follow-up (Figure 4). The greatest value was at the 6-month follow-up with less than $1^{\circ}$ difference at any point in the mean values throughout 60 -month follow-up. In the fusion group, the mean ROM was less than $2^{\circ}$ at 6 week follow-up and remained stable throughout the 60-month period. Left and right side bending was maintained in the TDR group at values slightly greater than the preoperative mean. In the ACDF group, lateral bending was decreased by 6 weeks after surgery and remained less than $2^{\circ}$ throughout followup.

The percentage of patients with ASD was less in the TDR group at both the superior and inferior adjacent levels compared to the ACDF group at all annual follow-up visits. The values were significantly different at the inferior adjacent segment at all annual visits (Figure 5). At the superior level, the difference was significantly lower in the TDR group at 48 and 60 months.

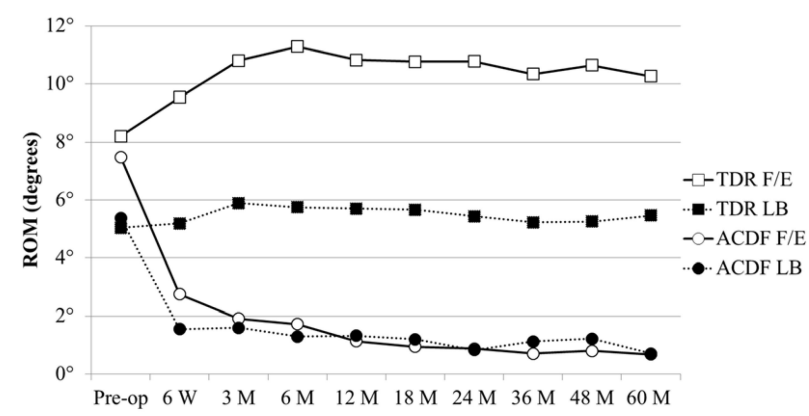

Fig. 4. Mean range of motion of the operated level.

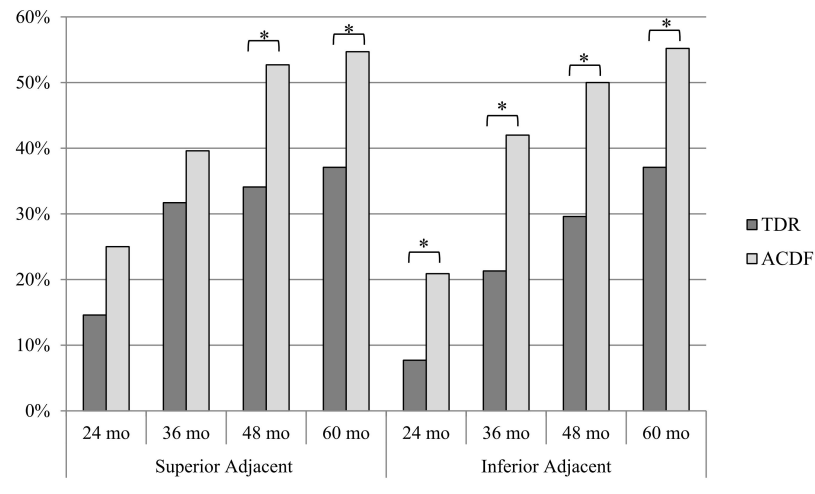

Fig. 5. The percentage of patients with adjacent segment degeneration at the superior or inferior adjacent level. *Statistical significance determined by Mann-Whitney U test, $\mathrm{p}<0.05$. 
The rate of Grade $4 \mathrm{HO}$ at the index level at 60-month follow-up was $8.5 \%$.

\section{Discussion}

Results of this randomized, controlled, FDA IDE clinical trial with 60-month follow-up found TDR with Mobi-C produced results noninferior to ACDF, and better outcomes on some measures at various time points including NDI and pain scales at early follow-up points, the subsequent surgery rate and adjacent segment degeneration at later follow-up points. These results are consistent with other studies comparing TDR with ACDF with 4 to 8 years follow-up. ${ }^{10-12}$ In the current study, as in the others, significant improvement was seen at early follow-up and maintained throughout long-term follow-up.

The flexion/extension mean range of motion at the operated TDR segment increased after surgery and remained stable throughout 5-year follow-up. HO severe enough to measurably limit motion was found in $8.5 \%$ of patients 5 years after TDR surgery. Previous studies have shown a variable rate of $\mathrm{HO}$ formation with unclear clinical relevance. ${ }^{22-24}$ One study with comparable follow-up reported a similar rate of $\mathrm{HO}^{25}$ While undesirable, $\mathrm{HO}$ does not appear to greatly impact clinical outcomes. ${ }^{26,27}$ Considering that severe $\mathrm{HO}$ results in essentially a fusion, the clinical results may also be similar to ACDF. The development of $\mathrm{HO}$ may be managed with greater attention paid to complete endplate coverage,${ }^{28}$ meticulous surgical technique minimizing uncovered bleeding bone, and prophylactic use of nonsteroidal anti-inflammatory drugs (NSAIDs).

The reoperation rate was significantly lower in the TDR group than in the ACDF group. This has been previously reported in other studies. ${ }^{13,14,29}$ In studies specifically addressing reoperation rates, authors found that the primary reason for reoperation in ACDF patients is symptomatic pseudoarthrosis. Symptomatic ASD was also a common reason for subsequent surgery. ${ }^{13,14}$ In the current study, a frequent reason for surgery at the index level in the ACDF group was symptomatic pseudoarthrosis, the risk of which is eliminated with TDR. Similar to the studies on reoperations, ASD was a reason for reop- eration in both the TDR and ACDF groups, but was the most frequent reason for reoperation in the ACDF group. The relationship of TDR or ACDF and ASD is not fully understood. In the classic study by Hilibrand et al, the rate of ASD was calculated to $2.9 \%$ per year. ${ }^{30}$ Results of the current study suggest a higher rate. This may be related to several factors such as differences in surgical technique, quality of images available, and/or differences in the assessment methods used to evaluate the adjacent segment. While TDR does not eliminate the risk of ASD, it does appear to be associated with a lower occurrence. Risk factors for developing ASD after cervical TDR have been found to include poor bone quality and the presence of lumbar disc degeneration. ${ }^{31}$ In many trials evaluating TDR, including the current study, poor bone quality was an exclusion criterion. The reported association of cervical ASD with lumbar disc degeneration was interesting and may represent patients with genetic and/or systemic risk factors for disc degeneration, which may impact the level adjacent to the index surgery. Luo et al. recently published a meta-analysis of prospective, randomized studies with 24-month follow-up addressing ASD in single-level TDR vs. ACDF. ${ }^{32}$ They concluded that TDR was associated with a significantly lower rate of ASD and a significantly lower rate of reoperation for ASD.

Cost can be a deciding factor when considering treatment options. Due to challenges in collecting comprehensive costs data as well as outcome data, costs studies are very difficult to conduct and often have different methods based on data availability. Several studies have compared the cost of single-level cervical TDR to ACDF ${ }^{33-37}$ Most of the studies found lower costs associated with TDR. A large-scale cost analysis of single-level TDR vs. ACDF has been conducted based on data collected from a Blue Health claims database..$^{34}$ Over the course of follow-up, the total treatment cost paid by insurers was significantly less for the TDR group. Factors impacting the lower costs were that the TDR group had lower readmission rates and lower cost of the index surgery. Qureshi et al. found that TDR and ACDF were both cost effective treatments, and that TDR would become more cost-effective than ACDF over an extended period. ${ }^{37}$ Ament et al. have recently reported

Downloaded from http://ijssurgery.com/ by guest on April 26, 2023 
that the cost of 2-level cervical TDR was also less expensive than ACDF. ${ }^{38}$ The current study found lower reoperation rate associated with TDR which may be associated with lower cost.

\section{Conclusion}

Five-year results showed improvements in pain and function are maintained in both treatment groups. In comparison to ACDF, the TDR group preserved motion and patients exhibited lower rates of adjacent segment degeneration through 60 months. Also, a significantly lower rate of subsequent surgeries was seen in the TDR group, indicating an additional benefit of this treatment option. This study presents Level I evidence demonstrating the safety and efficacy of single-level TDR with Mobi-C as an alternative to ACDF.

\section{Acknowledgements}

The authors would like to thank the following study investigators for their contributions to the study: Reginald J. Davis, M.D., Greater Baltimore Neurosurgical Associates, Baltimore, Maryland; Gregory A. Hoffman, M.D., Orthopaedics Northeast, Fort Wayne, Indiana; Steven E. Gaede, M.D., Oklahoma Brain and Spine Institute, Tulsa, Oklahoma; Ralph F. Rashbaum, M.D., Texas Back Institute, Plano, Texas; Daniel L. Peterson, M.D., Austin Brain and Spine, Austin, Texas; John K. Stokes, M.D., Seton Spine and Scoliosis Center, Austin, Texas; Charlie Gordon, M.D., Texas Spine and Joint Hospital, Tyler, Texas; Arnold Schwartz, M.D., Orthopedic Spine Care of Long Island, Huntington Station, New York; Ali Araghi, M.D., The Core Institute, Phoenix, Arizona; David Tahernia, M.D., Desert Orthopedic Center, Rancho Mirage, California; Hazem Eltahawy, M.D., University Neurologic Systems, Wayne State University, Detroit, Michigan; Reginald Tall, M.D., Southeastern Clinical Research, Orlando, Florida; Douglas Wong, M.D., Panorama Orthopedics \& Spine Center, Golden, Colorado; Gerald Schell, M.D., St. Mary's of Saginaw, Field Neurosciences Institute, Saginaw, Michigan; Michael Ramsey, M.D., West Texas Spine, Odessa, Texas; B. Christoph Meyer, M.D., Houston Orthopedic Hospital, Bellaire, Texas; Robert McLain, M.D., Cleve- land Clinic, Cleveland, Ohio; Jon Park, M.D., Stanford Hospital and Clinics, Stanford, California; Ed Simmons, M.D., Simmons Orthopaedics and Spine Associates, Buffalo, New York; Mark Stern, M.D., California Institute of Neurological Surgery, Escondido, California; Phillip S. Yuan, M.D., Memorial Orthopaedic Surgical Group, Long Beach, California; and Guy O. Danielson III, M.D., Texas Spine and Joint Hospital, Tyler, Texas.

\section{References}

1. Coric D, Nunley PD, Guyer RD, et al. Prospective, randomized, multicenter study of cervical arthroplasty: 269 patients from the Kineflex $\mid \mathrm{C}$ artificial disc investigational device exemption study with a minimum 2-year follow-up. J Neurosurg Spine 2011;15:348-58.

2. Murrey D, Janssen M, Delamarter R, et al. Results of the prospective, randomized, controlled multicenter Food and Drug Administration Investigational Device Exemption study of the ProDisc-C total disc replacement versus anterior discectomy and fusion for the treatment of 1-level symptomatic cervical disc disease. Spine J 2009;9:275-86.

3. Mummaneni PV, Burkus JK, Haid RW, et al. Clinical and radiographic analysis of cervical disc arthroplasty compared with allograft fusion: A randomized controlled clinical trial. J Neurosurg Spine 2007;6:198-209.

4. Phillips FM, Lee JY, Geisler FH, et al. A prospective, randomized, controlled clinical investigation comparing PCM cervical disc arthroplasty with anterior cervical discectomy and fusion. 2-year results from the US FDA IDE clinical trial. Spine 2013;38:E907-18.

5. Hisey MS, Bae HW, Davis R, et al. Multi center, prospective, randomized, controlled investigational device exemption clinical trial comparing Mobi $\mathrm{C}^{\circledR}$ cervical artificial disc to anterior discectomy and fusion in the treatment of symptomatic degenerative disc disease in the cervical spine. Int J Spine Surg 2014;8:http://dx.doi.org/10.14444/1007.

6. Vaccaro A, Beutler W, Peppelman W, et al. Clinical outcomes with selectively constrained SECURE$\mathrm{C}$ cervical disc arthroplasty: Two-year results from a prospective, randomized, controlled, multicenter In- 
vestigational Device Exemption study. Spine 2013;38:2227-39.

7. Zhang X, Zhang X, Chen C, et al. Randomized, controlled, multicenter, clinical trial comparing Bryan cervical disc arthroplasty with anterior cervical decompression and fusion in China. Spine 2012;37:433-8.

8. Rozankovic M, Marasanov SM, Vukic M. Cervical disc replacement with Discover versus fusion in a single level cervical disc disease: A prospective single center randomized trial with a minimum two-year follow-up. J Spinal Disord Tech, in press.

9. Aghayev E, Barlocher C, Sgier F, et al. Five-year results of cervical disc prostheses in the SWISSspine registry. Eur Spine J 2013;22:1723-30.

10. Janssen ME, Zigler JE, Spivak JM, et al. ProDisc-C total disc replacement versus anterior cervical discectomy and fusion for single-level symptomatic cervical disc disease: Seven-year follow-up of the prospective randomized U.S. Food and Drug Administration Investigational Device Exemption study. J Bone Joint Surg Am 2015;97:1738-47.

11. Burkus JK, Traynelis VC, Haid RW, Jr., et al. Clinical and radiographic analysis of an artificial cervical disc: 7-year follow-up from the Prestige prospective randomized controlled clinical trial: Clinical article. J Neurosurg Spine 2014;21:516-28.

12. Quan GM, Vital JM, Hansen S, et al. Eight-year clinical and radiological follow-up of the Bryan cervical disc arthroplasty. Spine 2011;36:639-46.

13. Blumenthal SL, Ohnmeiss DD, Guyer RD, et al. Re-operations in cervical total disc replacement compared with anterior cervical fusion: Results compiled from multiple prospective FDA IDE trials conducted at a single site. Spine 2013;38:1177-82.

14. Delamarter RB, Zigler J. Five-year reoperation rates, cervical total disc replacement versus fusion, results of a prospective randomized clinical trial.

Spine 2013;38:711-7.

15. Zigler JE, Delamarter R, Murrey D, et al. ProDisc-C and anterior cervical discectomy and fusion as surgical treatment for single-level cervical symptomatic degenerative disc disease: Five-year results of a Food and Drug Administration study. Spine 2013;38:203-9.

16. Jawahar A, Cavanaugh DA, Kerr EJ, 3rd, et al. Total disc arthroplasty does not affect the incidence of adjacent segment degeneration in cervical spine: Results of 93 patients in three prospective randomized clinical trials. Spine J 2010;10:1043-8.

17. Hisey MS, Bae HW, Davis RJ, et al. Prospective, randomized comparison of cervical total disk replacement versus anterior cervical fusion: Results at 48 months follow-up. J Spinal Disord Tech 2015;28:E237-43.

18. Kellgren JH, Lawrence JS. Radiological assessment of osteo-arthrosis. Ann Rheum Dis 1957;16:494-502.

19. McAfee PC, Cunningham BW, Devine J, et al. Classification of heterotopic ossification (HO) in artificial disk replacement. J Spinal Disord Tech 2003;16:384-9.

20. Mehren C, Suchomel P, Grochulla F, et al. Heterotopic ossification in total cervical artificial disc replacement. Spine 2006;31:2802-6.

21. Jackson RJ, Davis RJ, Hoffman GA, et al. Subsequent surgery rates after cervical total disc replacement using a Mobi-C ${ }^{\circledR}$ cervical disc prosthesis versus anterior cervical discectomy and fusion: A prospective randomized clinical trial with five-year followup. J Neurosurg Spine, in press.

22. Leung C, Casey AT, Goffin J, et al. Clinical significance of heterotopic ossification in cervical disc replacement: A prospective multicenter clinical trial. Neurosurgery 2005;57:759-63.

23. Cho YH, Kim KS, Kwon YM. Heterotopic ossification after cervical arthroplasty with ProDisc-C: Time course radiographic follow-up over 3 years. Korean J Spine 2013;10:19-24.

24. Guerin P, Obeid I, Bourghli A, et al. Heterotopic ossification after cervical disc replacement: Clinical significance and radiographic analysis. A prospective study. Acta Orthop Belg 2012;78:80-6. 25. Walraevens J, Demaerel P, Suetens P, et al. Longitudinal prospective long-term radiographic followup after treatment of single-level cervical disk disease with the Bryan cervical disc. Neurosurgery 2010;67:679-87.

26. Rihn JA, Radcliff K, Hipp J, et al. Radiographic variables that may predict clinical outcomes in cervical disc replacement surgery. J Spinal Disord Tech 2015;28:106-113.

27. Chen J, Wang X, Bai W, et al. Prevalence of heterotopic ossification after cervical total disc arthro- 
plasty: A meta-analysis. Eur Spine J 2012;21:674-80. 28. Nunley P, Cavanaugh D, Ker EJ, et al. Heterotopic ossification and endplate sizing in one-level CDA patients: Patient outcomes from a randomized, prospective, clinical trial. International Society for the Advancement of Spine Surgery. San Diego, CA, 2015.

29. Burkus JK, Haid RW, Traynelis VC, et al. Longterm clinical and radiographic outcomes of cervical disc replacement with the Prestige disc: Results from a prospective randomized controlled clinical trial. $J$ Neurosurg Spine 2010;13:308-18.

30. Hilibrand AS, Carlson GD, Palumbo MA, et al. Radiculopathy and myelopathy at segments adjacent to the site of a previous anterior cervical arthrodesis. J Bone Joint Surg Am 1999;81:519-28.

31. Nunley PD, Jawahar A, Kerr EJ, 3rd, et al. Factors affecting the incidence of symptomatic adjacent level disease in cervical spine after total disc arthroplasty: 2 - 4 years follow-up of 3 prospective randomized trials. Spine 2012;37:445-51.

32. Luo J, Gong M, Huang $S$, et al. Incidence of adjacent segment degeneration in cervical disc arthroplasty versus anterior cervical decompression and fusion meta-analysis of prospective studies. Arch $\mathrm{Or}$ thop Trauma Surg 2015;135:155-60.

33. White AP, Biswas D, Smart LR, et al. Utility of flexion-extension radiographs in evaluating the degenerative cervical spine. Spine 2007;32:975-9.

34. Radcliff K, Zigler J, Zigler J. Costs of cervical disc replacement versus anterior cervical discectomy and fusion for treatment of single-level cervical disc disease: An analysis of the Blue Health Intelligence database for acute and long-term costs and complications. Spine 2015;40:521-9.

35. McAnany SJ, Overley S, Baird EO, et al. The 5-year cost-effectiveness of anterior cervical discectomy and fusion and cervical disc replacement: A Markov analysis. Spine 2014;39:1924-33.

36. Warren D, Andres T, Hoelscher C, et al. Costutility analysis modeling at 2-year follow-up for cervical disc arthroplasty versus anterior cervical discectomy and fusion: A single-center contribution to the randomized controlled trial. Int J Spine Surg

2013;7:e58-e66.

37. Qureshi SA, McAnany S, Goz V, et al. Costeffectiveness analysis: Comparing single-level cervi- cal disc replacement and single-level anterior cervical discectomy and fusion. J Neurosurg Spine 2013;19:546-54.

38. Ament J. Cost utility analysis of the cervical artificial disc vs fusion for the treatment of 2-level symptomatic degenerative disc disease: 5-year follow-up. Neurosurgery, in press.

\section{Disclosures}

Hyun Bae has acted as contultant to and has received royalties from LDR. Robert Jackson reports owning stock in Medtronic, Globus, Johnson and Johnson, and LDR and receiving royalties from Globus and personal teaching fees from LDR. Michael Hisey reports fees from faculty for Mobi-C training. Kee Kim reports personal fees from Globus, personal fees from LDR, personal fees from LDR, Globus, Spinal USA, personal fees from Molecular Matrix, personal fees from ZimmerBiomet, personal fees from InVivo Therapeutics, other from Target Tape, other from Asubio, InViVo Theapeutics, Globus, outside the submitted work. Donna Ohnmeiss is employed by an organization that hsa received institutional research support from the study sponsor. Pierce Nunley reports royalties from Osprey Biomedical, LDR Spine, and K2M; stock ownership in Amedica, Safewire, Paradigm Spine, Spineology; speaking or teaching fees from K2M, LDR Spine; Scientific Advisory Board of K2M, consultancy for Vertiflex, LDR Spine, K2M; and has received institutional support for Nutech Medical, Pfizer, Seikagaku Corporation, Spinal Kinetics, K2M, Mesoblast, Simplify, Globus, SI-Bone, and LDR Spine. Jack Zigler receives royalties from Zimmer Sine, and has taught and consulted for DePuy Synthes, Medtronic, and Simplify; he has stock options in Spinal Kinetics.

\section{Corresponding Author}

Michael S. Hisey, M.D. Texas Back Institute, 2817 S. Mayhill Rd. \#100, Denton, TX 76208. orthoboss@aol.com.

Published 26 February 2016.

This manuscript is generously published free of charge by ISASS, the International Society for the Advancement of Spine Surgery. Copyright @ 2016

Downloaded from http://ijssurgery.com/ by guest on April 26, 2023 
ISASS. To see more or order reprints or permissions, see http://ijssurgery.com. 